\title{
Effect of Faculty Development Activities on Dental Hygiene Faculty Perceptions of and Teaching About Motivational Interviewing: A Pilot Study
}

\author{
Michelle Arnett, RDH, MS; Dina Korte, RDH, MS; Philip S. Richards, DDS, MS; \\ Berna Saglik, DDS, MS; L. Susan Taichman, RDH, PhD; Janet S. Kinney, RDH, MS; \\ Anne E. Gwozdek, RDH, MA
}

Abstract: The aims of this pilot study were to assess dental hygiene faculty members' perceptions of the importance of motivational interviewing (MI) and their confidence in teaching students about MI and to determine the effect of MI training sessions on those perceptions. Participants were a convenience sample of all 16 dental hygiene faculty members who teach in the clinic at the University of Michigan School of Dentistry. Participants' perceptions were assessed prior to a workshop in MI (pretest), immediately after the workshop (posttest 1), and eight months after the workshop, at the end of the academic year (posttest 2). During the same period, some of the workshop participants took part in team grading sessions of audio recordings of student-patient MI interactions. The results showed that the majority of the faculty members perceived it was important to personally embrace the overall spirit of MI during patient care, and they were confident supporting students as well. Their ratings for embracing the spirit of MI increased from pretest to posttest 1, but slightly decreased at posttest 2 . This trend was also seen in their assessment of the importance of and their confidence in teaching the eight MI strategies over time. Among the workshop participants, $56 \%$ were part of team grading; they reported the most helpful professional development activities overall were team grading (58\%) and the workshop (25\%). These results suggest the importance of making use of a variety of faculty development activities and of introducing appropriate follow-up to training sessions over time to ensure long-lasting effects. Future research using carefully designed, multi-institution, longitudinal studies is needed to determine the most effective ways to prepare dental hygiene faculty members to educate their students about MI.

\begin{abstract}
Ms. Arnett is a 2016 graduate of the Master of Science in Dental Hygiene Program and Adjunct Clinical Lecturer, Department of Periodontics and Oral Medicine, University of Michigan School of Dentistry; Ms. Korte is Adjunct Clinical Lecturer, Department of Periodontics and Oral Medicine, University of Michigan School of Dentistry; Dr. Richards is Clinical Professor, Department of Periodontics and Oral Medicine, University of Michigan School of Dentistry; Dr. Saglik is Clinical Associate Professor, Department of Biologic and Materials Sciences, University of Michigan School of Dentistry; Dr. Taichman is Adjunct Clinical Associate Professor, Department of Periodontics and Oral Medicine, University of Michigan School of Dentistry; Prof. Kinney is Director of Dental Hygiene and Clinical Associate Professor, Department of Periodontics and Oral Medicine, University of Michigan School of Dentistry; and Prof. Gwozdek is retired Clinical Assistant Professor and Director of Dental Hygiene Graduate and Degree Completion Programs, Department of Periodontics and Oral Medicine, University of Michigan School of Dentistry. Direct correspondence to Ms. Michelle Arnett, University of Michigan School of Dentistry, 1011 N. University, Room 3066, Ann Arbor, MI 48109; 734-718-5107; arnetmic@umich.edu.
\end{abstract}

Keywords: dental hygiene education, allied dental education, motivational interviewing, faculty development

Submitted for publication 11/8/16; accepted 2/28/17 doi: 10.21815/JDE.017.048

$\mathrm{O}$ ral diseases such as periodontal disease and caries can be prevented or reduced because, in addition to medical treatments, there is a complex relationship between an individual's behavior and his or her lifestyle that may contribute to oral diseases. ${ }^{1-4}$ As a result, there are evidence-based approaches to support behavior change that are effective in chronic disease reduction. ${ }^{1,3-8}$ Health professionals, including dental hygienists, need to understand health behavior theories and concepts in order to do their jobs effectively. $3,5,7,9-11$ Advice-giving educational methods generally do not motivate patients and can potentially discourage them from making a change. ${ }^{9,11}$ Croffoot et al. found that information provided by clinicians to patients was not substantial enough to cause a health behavior change. ${ }^{10}$ In addition, Brand 
et al.'s study found that informing patients of negative consequences from non-adherence to professional advice did not promote or encourage lifelong positive behavior change. $^{9}$

In contrast to those methods, behavioral science research indicates that effective methods to change a behavior include eliciting intrinsic motivation through patient-centered counseling. Motivational interviewing (MI) is a patient-centered, collaborative counseling approach, focusing on strengthening a patient's motivation for a positive behavior change. ${ }^{6}$ It allows the health care provider to convey a sense of partnership, acceptance, compassion, and evocation known as the "spirit of MI." This feeling supports patients in becoming responsible for their own health and developing autonomy for their decisions.

Eight MI strategies can be used to help guide patients to achieve a behavior change. The first four are the use of open-ended questions, affirmations, reflective listening, and summaries (known by the acronym "OARS"). ${ }^{10}$ Open-ended questions are those that cannot be answered with yes or no statements from the patient. ${ }^{5,10}$ Posing a question that provides an opportunity to craft a response allows the clinician to understand the patient's perception. ${ }^{5}$ Affirmations are achieved by giving encouragement to and acknowledgment of the patient's strengths. When clinicians affirm a patient, it enhances rapport and helps patients build confidence in changing a behavior. Reflective listening allows a clinician to show an understanding of a patient's perceptions, ambivalence, and efforts. ${ }^{10}$ It also helps patients hear their own statements of thoughts and feelings in a different form, which may assist in their internal motivation to change a behavior. ${ }^{6}$ Summaries help to close the MI session, ensure the clinician understands the patient's perspective, and connects the information provided by the patient. ${ }^{5}$ According to Croffoot et al., using OARS is important in obtaining desired goals when implementing MI during patient interactions. ${ }^{10}$

The next four MI strategies are change talk, importance ruler, elaboration, and supporting selfefficacy, all of which assist patients in overcoming their ambivalence. ${ }^{6}$ Change talk occurs when the patient's own statements identify a behavior that needs to be modified. The importance ruler can be used to ask an evocative question and have the patient assess his or her level of importance and/or confidence to change a behavior on a scale from 0 to 10. Asking patients to elaborate on their decisions is a strategy to evoke intrinsic motivation. Supporting self-efficacy is used to encourage and praise patients' accomplishments, building confidence in their ability to change a behavior. ${ }^{5,8}$

MI can be and is used by a variety of health professionals including those in oral health care. .,6,9- $^{-}$ ${ }^{17}$ Due to time constraints, an alternative approach used in health care is brief MI (BMI), a derivative of MI. ${ }^{8} \mathrm{BMI}$ is intended for use by providers who have limited time (five to ten minutes) to discuss behavior change with patients. The focus is on the collaborative spirit of MI, allowing the patient to think about the benefits and challenges of change. The goal of both $\mathrm{MI}$ and BMI is to evoke a change from within the individual to improve his or her health. ${ }^{6,8}$

As increased emphasis is placed on improvement of oral health and prevention of oral and systemic diseases, dental hygienists need to position themselves as effective providers of counseling regarding behaviors that impact their patients' oral health. ${ }^{1,2}$ The integration of MI training in dental hygiene curricula may improve students' use of such counseling in their professional roles. ${ }^{18}$

To adequately implement MI, faculty members need training. ${ }^{17-20}$ Curry-Chiu et al. found that faculty training and buy-in were important aspects of implementing MI in a curriculum. ${ }^{18}$ The combination of MI training with coaching and feedback has been found to increase retention of MI skills. ${ }^{17,20}$ Also, the spirit and delivery of MI were found to improve when faculty training sessions occurred..$^{19}$ Furthermore, Croffoot et al. reported that students' ability to apply MI skills improved when their faculty members had received MI training. ${ }^{10}$ In addition, Kenny et al. found that a significant aspect of medical students' ability to learn was influenced by positive role modeling by faculty members. ${ }^{21}$ In Kenny et al.'s study, learning was achieved when students observed those in professional roles and then applied those observations to their own practice. Curry-Chiu et al. found that faculty involvement in embracing the spirit of MI had an effect on dental hygiene graduates' desire to implement MI in their professional practice. ${ }^{18}$ The aims of our pilot study were to assess dental hygiene faculty members' perceptions of the importance of motivational interviewing (MI) and their confidence in teaching students about MI and to determine the effect of MI training sessions on those perceptions. We hypothesized that participation in MI faculty development activities would increase the participants' perceptions of MI importance and their confidence in facilitating students' MI interactions with patients. 


\section{Materials and Methods}

The University of Michigan (U-M) Institutional Review Board determined that this study was exempt from oversight (HUM00065102). A convenience sample of all $16 \mathrm{U}-\mathrm{M}$ dental hygiene program faculty members who taught in the clinic in 2014-15 participated in the study. These faculty members were directly involved with supporting students' delivery of MI during patient care.

In 2013, the U-M dental hygiene program's health behavior change curriculum was enhanced with a special focus on MI. Prior to this curricular change, students had only one 50-minute didactic session that was partially devoted to MI. The enhancement took place over four semesters of the six-semester dental hygiene program and included 14 didactic sessions that were 50 minutes each. In addition, three semesters included a clinical application assessment. Two of the clinical assessments were graded audio recordings of student-patient MI interactions. One assessment included the application of MI with a standardized patient instructor (SPI), focusing on tobacco cessation. The Class of 2015 was the first cohort to participate fully in the enhanced curriculum. A study by Mills et al. assessed the student-related outcomes of this enhanced MI curriculum. ${ }^{22}$

Professional development activities in MI for the U-M dental hygiene faculty were added to support the health behavior change curricular enhancement. Faculty members participated in MI workshops in 2012 and 2014 with a focus on increasing their understanding of MI and how to integrate it into their teaching; this study focused on the impact of the 2014 workshop. The 2012 workshop was a two-day (14-hour) event, and the 2014 workshop was a fivehour session facilitated by faculty members from the University of Missouri-Kansas City (UMKC) School of Dentistry who had extensive experience with MI. This training was designed to provide U-M dental hygiene faculty members with better understanding of MI as well as to enhance their ability to support students' application in clinical care. During these sessions, faculty members participated in activities to strengthen their understanding of this counseling approach. They were also provided with opportunities to apply the MI grading rubric to sample recordings and to provide feedback.

In the three semesters following the $2014 \mathrm{MI}$ workshop, the same dental hygiene faculty members were given the opportunity to participate in team grading. Beginning that fall, those faculty members - in a small team setting that included the MI faculty coordinator as the facilitator - met to grade and discuss feedback on audio recordings of studentpatient MI interactions. Four to 12 sessions of 90 minutes each were offered each semester to accommodate faculty availability. During these sessions, faculty members listened to students' recordings and graded them using the Motivational Interviewing Clinical Audio Recording Rating Form adapted from the Motivational Interviewing Treatment Integrity (MITI) code. ${ }^{23}$ This rating form's criteria assessed students' adherence to the eight MI strategies as well as maintaining the spirit of MI through rapport, empathy, and respecting autonomy. Also in fall 2014, the faculty began evaluating students on their overall application of the spirt of MI as an element of their daily grade in clinic.

For this study, the dental hygiene faculty members completed evaluation instruments on four occasions. Three of the instruments were the pretest, posttest 1 , and posttest 2 . All three of these tests used the same survey instrument, with the additions to posttest 2 explained below. The fourth instrument was the Motivational Interviewing Qualitative Faculty Questionnaire. The pretest, posttest 1, and posttest 2 were adapted from an instrument designed by the UMKC Division of Dental Hygiene. Modifications were completed in consultation with U-M's Center for Research on Learning and Teaching. To determine content validity, we pilot tested the instruments with two faculty members who had been involved with MI faculty development training. Modifications were made based on their feedback.

The pretest was conducted in August 2014 prior to the MI workshop, and posttest 1 was conducted immediately following that session. Posttest 2 was conducted nearly eight months later, in April 2015, at the conclusion of the 2014-15 academic year. The fourth evaluation instrument was administered after the third semester of team grading in November 2015.

On the pretest, posttest 1 , and posttest 2 , faculty members used a five-point rating scale to self-assess their perceptions of the importance of MI strategies and their confidence in supporting students' application of MI strategies and embracing the spirit of MI. The MI strategies named in these evaluation instruments were the following: using open-ended questions, listening reflectively, making affirmations, summarizing, eliciting change talk, using the importance ruler, asking for elaboration, and enhancing 
self-efficacy. In addition, posttest 2 had questions to evaluate the faculty member's own perceptions regarding modeling the spirit of MI. The fourth instrument used, the Motivational Interviewing Qualitative Faculty Questionnaire, asked for recommendations on how to maintain faculty confidence, identify time management strategies to provide feedback to students in clinic, assist students in recognizing faculty modeling of MI, and enhance their influence on students' application of the spirit of MI.

Statistical Package for the Social Sciences (SPSS) version 22 was used for data analysis. Descriptive statistics including mean and standard error (SE) were used to report the results. The median and semi-interquartile range (SIV) were determined for participants' perceptions of importance of and confidence in facilitating the eight MI strategies. The Wilcoxon signed-rank test was used to determine differences in average ranks for comparisons for three time spans: from pretest to posttest $1\left(\mathrm{~T}_{1}\right)$, from pretest to posttest $2\left(\mathrm{~T}_{2}\right)$, and from posttest 1 to posttest $2\left(\mathrm{~T}_{3}\right)$. Significance was set at $\mathrm{p}<0.05$. Qualitative data were categorized into themed responses by two independent raters.

\section{Results}

Information on the participants' demographic and professional characteristics is shown in Table

Table 1. Faculty members' demographic and professional characteristics, by number and percentage of respondents to each item

\begin{tabular}{lcc} 
Characteristic & Response Option & Number $(\%)$ \\
\hline $\begin{array}{l}\text { Gender } \\
\mathrm{n}=16\end{array}$ & Female & $16(100 \%)$ \\
Age & Male & 0 \\
$\mathrm{n}=16$ & $21-30$ years & $3(19 \%)$ \\
& $31-40$ years & $3(19 \%)$ \\
& $41-50$ years & $4(25 \%)$ \\
& $51-59$ years & $1(6 \%)$ \\
Years practicing & years or more & $5(31 \%)$ \\
$\mathrm{n}=16$ & $<5$ years & $2(12.5 \%)$ \\
& $5-10$ years & $2(12.5 \%)$ \\
& $11-15$ years & $2(12.5 \%)$ \\
Employment & $>15$ years & $10(62.5 \%)$ \\
$n=16$ & Part-time & $13(81 \%)$ \\
Years teaching & Full-time & $3(19 \%)$ \\
$n=15$ & $<5$ years & $6(40 \%)$ \\
& $5-10$ years & $5(33 \%)$ \\
& $11-15$ years & $1(7 \%)$ \\
& $>15$ years & $3(20 \%)$ \\
& &
\end{tabular}

1. The participants' perceptions of the importance of and their confidence in supporting students' embracing the spirit of MI is shown in Figure 1. Mean scores regarding the importance of MI were $4.9 \pm 0.07$ at the pretest, $5.0 \pm 0.06$ at posttest 1 , and $4.8 \pm 0.12$ at posttest 2 . The mean of all three ratings was 4.9 for the participants' perceptions of importance and 4.0 for their confidence (not shown).

The participants' perceptions of the importance of and their confidence in facilitating the eight MI strategies with students are shown in Table 2. Their perception of the importance of the eight MI strategies stayed the same over time. However, the SIV decreased for the items "use open-ended questions" and "elicit change talk" immediately following MI training. By the conclusion of the academic year, the SIV increased for the items "summarize," "elicit change talk," and "use of the importance ruler." There was no statistically significant difference for any of the three comparisons $\left(\mathrm{T}_{1}, \mathrm{~T}_{2}\right.$, or $\left.\mathrm{T}_{3}\right)$. Effect size calculated for the comparison $\mathrm{T}_{3}$ using $\mathrm{r}$-squared ranged from 0.10 to 0.20 .

The participants' perceptions of their confidence remained the same as prior to training immediately following the workshop (Table 2). The SIV increased for the item "ask for elaboration" and decreased for the item "use the importance ruler" immediately following MI training. By the end of the academic year, the participants' median score on their confidence had decreased for the items "ask for elaboration" and "enhance self-efficacy." In addition, the SIV increased for the items "make affirmations," "summarize," "elicit change talk," "use the importance ruler," "ask for elaboration," and "enhance self-efficacy." The difference between the comparisons $\mathrm{T}_{1}, \mathrm{~T}_{2}$, and $\mathrm{T}_{3}$ were not statistically significant. Effect size calculated at $\mathrm{T}_{3}$ using $\mathrm{r}$-squared ranged from 0.01 to 0.20 .

On three occasions (pretest, posttest 1, and posttest 2), the same questions were asked of the participants regarding their perceptions of students' ability to use MI strategies and the amount of time in clinic to incorporate MI. In addition, the participants were asked their perspectives regarding their own skills and ability to be a positive influence to facilitate students' use of MI strategies in clinic (Table 3). On the question "I believe students have enough time in clinic to incorporate MI strategies with their patients," the median score was 3.0 (SIV $0.5)$ at pretest, $4.0(1)$ at posttest 1 , and 3.0 (1) at posttest 2 . The difference found in the comparison $\mathrm{T}_{1}$ was statistically significant $(\mathrm{p}=0.03)$. Differences 


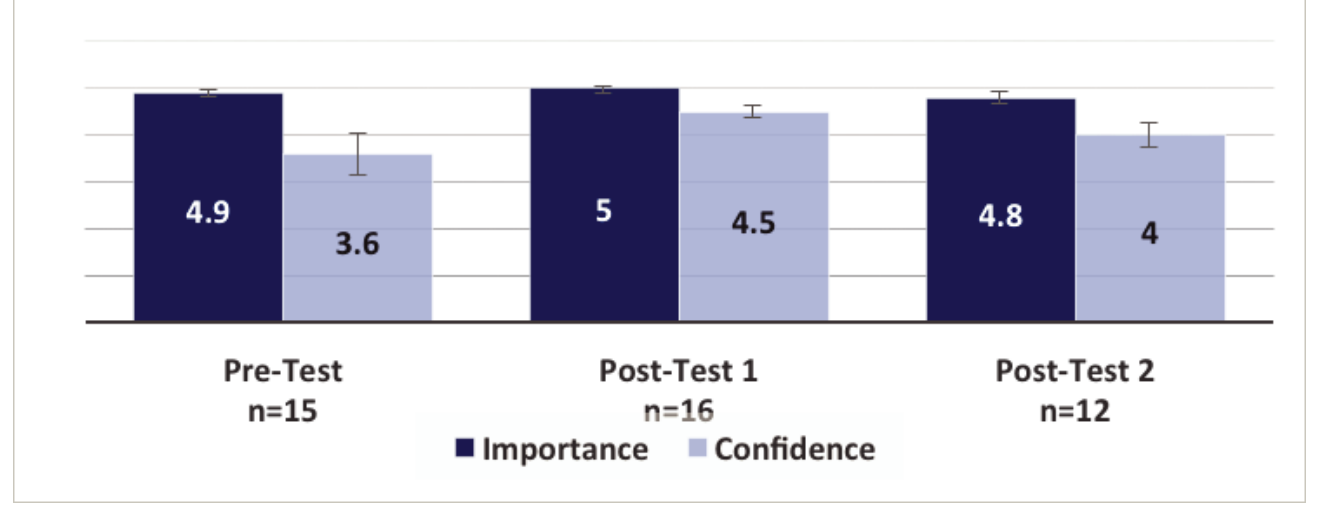

Figure 1. Faculty members' perceptions of the importance of supporting students' embrace of the spirit of motivational interviewing and their confidence in doing so, on the pretest, posttest 1, and posttest 2

Note: The spirit of motivational interviewing is defined as collaboration, showing empathy, supporting autonomy, acceptance, and client-centeredness during patient care. Response options on the importance question were $0=$ unable to answer, $1=$ not very important, $2=$ of little importance, $3=$ neutral, $4=$ somewhat important, and $5=$ very important. Response options on the confidence question were $0=$ unable to answer, $1=$ not at all confident, $2=$ little confidence, $3=$ neutral, $4=$ somewhat confident, and $5=$ very confident. Error bars represent the standard error.

were not statistically significant for $\mathrm{T}_{2}(\mathrm{p}=0.57)$ or $\mathrm{T}_{3}$ $(p=0.08)$. The effect size was 0.28 . On the question "I can have a positive influence on my students and their use of MI strategies in clinic," the median score was 4.0 (SIV 0.5) at pretest, $5.0(0.5)$ at posttest 2, and 4.0 (1) at posttest 3 . The difference found in the comparison $T_{3}$ was statistically significant $(\mathrm{p}=0.04)$. Differences were not statistically significance for $\mathrm{T}_{1}$ $(p=0.59)$ or $T_{2}(p=0.15)$. The effect size was 0.03 .

\section{Faculty Team Grading}

Faculty team grading of recorded MI studentpatient interactions took place during the fall 2014, winter 2015, and fall 2015 semesters. In these semesters, a total of 16 clinical faculty members could have participated in team grading. In fall 2014, there were 14 clinical faculty members employed. By winter 2015, two of those faculty members had left the university, and two new faculty members had been hired. There were no changes in the clinical faculty from winter 2015 to fall 2015.

Four team grading sessions were available in the fall 2014 semester, when there were 14 faculty members in the clinic (Table 4). Seven (50\%) of those did not participate in any sessions, and the other seven $(50 \%)$ participated in at least one session. The winter 2015 semester offered 12 team grading sessions, when there were 14 faculty members in the clinic. Of those, $57.2 \%(n=8)$ did not participate in any sessions, and $42.8 \%(n=6)$ participated in at least one session. During the fall 2015 semester, four team grading sessions were offered, when there were 14 faculty members in the clinic. Of those, 64\% participated in at least one session, and $36 \%(\mathrm{~N}=5)$ did not participate in any.

\section{Analysis of Qualitative Responses}

The qualitative responses on posttest 2 and the Motivational Interviewing Qualitative Faculty Questionnaire were combined for analysis at the end of the study period (Table 5). On posttest 2 , the participants reported that team grading 50\% $(n=7)$ and the MI workshop 36\% $(n=5)$ were most helpful in enhancing faculty support of student delivery of the spirit of MI during patient care. When asked about their ability to assess students' application of the spirit of MI, $69 \%(n=9)$ reported being limited by time constraints. However, $23 \%(n=3)$ reported they were able to assess students' application of the spirit of MI. In addition, $66 \%(n=4)$ reported they were able to model the spirit of MI on a limited basis, but time constraints on that were reported by one participant.

On the Motivational Interviewing Qualitative Faculty Questionnaire, 50\% $(n=4)$ of the respondents suggested continuing faculty development to help them maintain confidence in supporting students' use of MI. Two faculty members (25\%) suggested team grading continue to assist in maintaining their confidence. To help maintain a positive influence on students' use of MI during clinic, $37.5 \%(n=3)$ 
Table 2. Faculty members' perceptions of importance of motivational interviewing (MI) strategies and confidence in facilitating students' $\mathrm{MI}$ strategies $(\mathrm{N}=16)$

\begin{tabular}{|c|c|c|c|c|c|c|}
\hline MI Strategy & $\begin{array}{l}\text { Pretest } \\
\text { Median } \\
(\text { SIV })\end{array}$ & $\begin{array}{l}\text { Posttest } 1 \\
\text { Median } \\
\text { (SIV) }\end{array}$ & $\begin{array}{l}\text { Posttest } 2 \\
\text { Median } \\
(\text { SIV })\end{array}$ & $\begin{array}{c}\text { Wilcoxon } \\
\text { Signed Rank Test } \\
\mathrm{T}_{1} / \mathrm{T}_{2} / \mathrm{T}_{3}\end{array}$ & $\begin{array}{c}\mathrm{Z} \\
\text { Statistic } \\
\mathrm{T}_{3}\end{array}$ & $\begin{array}{c}\text { Effect } \\
\text { Size } \\
\mathrm{T}_{3}\end{array}$ \\
\hline \multicolumn{7}{|l|}{ Importance } \\
\hline Use open-ended questions & $5.0(0.5)$ & $5.0(0)$ & $5.0(0)$ & 0.08/0.08/1.0 & 0.00 & V \\
\hline Listen reflectively & $5.0(0)$ & $5.0(0)$ & $5.0(0)$ & 1.0/1.0/1.0 & 0.00 & V \\
\hline Make affirmations & $5.0(0.5)$ & $5.0(0.5)$ & $5.0(0)$ & $0.66 / 0.31 / 1.0$ & 0.00 & $\mathrm{~V}$ \\
\hline Summarize & $5.0(0)$ & $5.0(0)$ & $5.0(0.5)$ & 0.56/0.10/0.18 & -1.3 & 0.10 \\
\hline Elicit change talk & $5.0(0.5)$ & $5.0(0)$ & $5.0(1)$ & 0.48/0.23/0.06 & -1.9 & 0.17 \\
\hline Use the importance ruler & $4.0(1)$ & $4.0(1)$ & $4.0(1.5)$ & $1.0 / 0.37 / 0.33$ & -0.98 & 0.20 \\
\hline Ask for elaboration ("what else?") & $5.0(0.5)$ & $5.0(0.5)$ & $5.0(0.5)$ & 0.94/0.48/0.59 & -0.54 & 0.02 \\
\hline Enhance self-efficacy & $5.0(0.5)$ & $5.0(0.5)$ & $5.0(0.5)$ & $0.67 / 0.79 / 0.78$ & -0.28 & 0.04 \\
\hline \multicolumn{7}{|l|}{ Confidence } \\
\hline Use open-ended questions & $5.0(0.5)$ & $5.0(0.5)$ & $5.0(0.5)$ & 0.13/0.86/0.48 & -0.71 & 0.13 \\
\hline Listen reflectively & $5.0(0.5)$ & $5.0(0.5)$ & $5.0(0.5)$ & $0.48 / 0.74 / 0.48$ & -0.71 & 0.10 \\
\hline Make affirmations & $5.0(0.5)$ & $5.0(0.5)$ & $5.0(1)$ & $1.0 / 0.38 / 0.38$ & -0.88 & 0.16 \\
\hline Summarize & $5.0(0.5)$ & $5.0(0.5)$ & $5.0(1.5)$ & 0.33/0.36/0.07 & -1.8 & 0.14 \\
\hline Elicit change talk & $4.0(1)$ & $4.0(1)$ & $4.0(1.5)$ & $0.39 / 0.57 / 0.11$ & -1.6 & 0.09 \\
\hline Use the importance ruler & $4.0(1.5)$ & $4.0(1)$ & $4.0(1.5)$ & $0.47 / 0.77 / 0.49$ & -0.69 & 0.15 \\
\hline Ask for elaboration ("what else?") & $5.0(0.5)$ & $5.0(1)$ & $4.0(1.5)$ & $0.55 / 0.32 / 0.13$ & -1.5 & 0.01 \\
\hline Enhance self-efficacy & $5.0(1)$ & $5.0(1)$ & $4.0(1.5)$ & $0.64 / 0.51 / 0.30$ & -1.0 & 0.20 \\
\hline
\end{tabular}

Note: On importance items, response options were $0=$ unable to answer, $1=$ not very important, $2=$ of little importance, $3=$ neutral, $4=$ somewhat important, and $5=$ very important. On confidence items, response options were $0=$ unable to answer, $1=$ not at all confident, $2=$ little confidence, $3=$ neutral, $4=$ somewhat confident, and $5=$ very confident. Effect size was determined by $r$-squared test $(\mathrm{V}=\mathrm{variable}$ constant).

$\mathrm{SIV}=$ semi-interquartile value; $\mathrm{T}_{1}=$ pretest to posttest $1 ; \mathrm{T}_{2}=$ pretest to posttest $2 ; \mathrm{T}_{3}=$ posttest 1 to posttest 2

Table 3. Faculty members' perceptions about students' use of motivational interviewing (MI) and their own abilities to teach MI $(\mathrm{N}=16)$

\begin{tabular}{|c|c|c|c|c|c|c|}
\hline Item & $\begin{array}{l}\text { Pretest } \\
\text { Median } \\
\text { (SIV) }\end{array}$ & $\begin{array}{l}\text { Posttest } 1 \\
\text { Median } \\
\text { (SIV) }\end{array}$ & $\begin{array}{l}\text { Posttest } 2 \\
\text { Median } \\
\text { (SIV) }\end{array}$ & $\begin{array}{l}\text { Wilcoxon } \\
\text { Signed Rank Test } \\
\mathrm{T}_{1} / \mathrm{T}_{2} / \mathrm{T}_{3}\end{array}$ & $\begin{array}{l}\mathrm{Z} \\
\text { Statistic } \\
\mathrm{T}_{3}\end{array}$ & $\begin{array}{l}\text { Effect } \\
\text { Size } \\
\mathrm{T}_{3}\end{array}$ \\
\hline $\begin{array}{l}\text { I believe MI will help students achieve } \\
\text { behavior change with their patients. }\end{array}$ & $4.0(0.5)$ & $5.0(0.5)$ & $4.5(1)$ & $0.08 / 0.94 / 0.29$ & -1.0 & 0.00 \\
\hline $\begin{array}{l}\text { I believe students have enough time in } \\
\text { clinic to incorporate MI strategies with } \\
\text { their patients. }\end{array}$ & $3.0(0.5)$ & $4.0(1)$ & $3.0(1)$ & $0.03 * / 0.57 / 0.08$ & -1.7 & 0.28 \\
\hline $\begin{array}{l}\text { With proper education and training, } \\
\text { I believe students have the ability to } \\
\text { use Ml strategies with their patients. }\end{array}$ & $5.0(0.5)$ & $5.0(0.5)$ & $4.0(0.5)$ & $0.36 / 0.41 / 0.20$ & -1.3 & 0.08 \\
\hline $\begin{array}{l}\text { I have the skills needed to facilitate } \\
\text { students' use of MI strategies in clinic. }\end{array}$ & $4.0(1)$ & $4.5(0.5)$ & $4.0(0.5)$ & $0.17 / 0.55 / 0.62$ & -0.50 & 0.02 \\
\hline $\begin{array}{l}\text { I can have a positive influence on my } \\
\text { students and their use of MI strategies }\end{array}$ & $4.0(0.5)$ & $5.0(0.5)$ & $4.0(1)$ & $0.59 / 0.15 / 0.04^{*}$ & -2.1 & 0.03 \\
\hline
\end{tabular}

Note: Response options were $0=$ unable to answer, $1=$ strongly disagree, $2=$ disagree, $3=$ neutral, $4=$ agree, and $5=$ strongly agree. Effect size was determined by r-squared test.

$\mathrm{SIV}=$ semi-interquartile value; $\mathrm{T}_{1}=$ pretest to posttest $1 ; \mathrm{T}_{2}=$ pretest to posttest $2 ; \mathrm{T}_{3}=$ posttest 1 to posttest 2

*Statistically significant at $\mathrm{p}<0.05$ (two tailed) 
Table 4. Faculty members who participated in 2014-15 motivational interviewing team grading, by number and percentage of total potential participants in each semester

\begin{tabular}{|c|c|c|c|c|c|}
\hline \multicolumn{2}{|c|}{$\begin{array}{l}\text { Fall Semester } 2014 \\
\text { (4 Sessions) } \\
n=14\end{array}$} & \multicolumn{2}{|c|}{$\begin{array}{l}\text { Winter Semester } 2015 \\
\begin{array}{c}\text { (12 Sessions) } \\
\mathrm{n}=14\end{array}\end{array}$} & \multicolumn{2}{|c|}{$\begin{array}{l}\text { Fall Semester } 2015 \\
\text { (4 Sessions) } \\
n=14\end{array}$} \\
\hline $\begin{array}{l}\text { Number of } \\
\text { Sessions }\end{array}$ & $\begin{array}{c}\text { Number of } \\
\text { Participants (\%) }\end{array}$ & $\begin{array}{l}\text { Number of } \\
\text { Sessions }\end{array}$ & $\begin{array}{c}\text { Number of } \\
\text { Participants (\%) }\end{array}$ & $\begin{array}{l}\text { Number of } \\
\text { Sessions }\end{array}$ & $\begin{array}{c}\text { Number of } \\
\text { Participants (\%) }\end{array}$ \\
\hline 0 sessions & $7(50 \%)$ & 0 sessions & $8(57.2 \%)$ & 0 sessions & $5(36 \%)$ \\
\hline 1 session & $5(36 \%)$ & 1 session & 0 & 1 session & $3(21 \%)$ \\
\hline 2 sessions & 1 (7\%) & 2 sessions & $3(21.4 \%)$ & 2 sessions & $6(43 \%)$ \\
\hline 3 sessions & $1(7 \%)$ & 3 sessions & $3(21.4 \%)$ & 3 sessions & 0 \\
\hline
\end{tabular}

Table 5. Analysis of participants' qualitative responses regarding motivational interviewing (MI), with number and percentage of total responses to each item

\begin{tabular}{|c|c|c|c|}
\hline Instrument & Response & Theme & $\begin{array}{l}\text { Percentage } \\
\text { (number) }\end{array}$ \\
\hline \multirow[t]{3}{*}{ Posttest 2} & $\begin{array}{l}\text { MI activities and training that were most } \\
\text { helpful in enhancing faculty support of } \\
\text { student delivery of spirit of MI } \\
\text { (respondents=9, total responses=14) }\end{array}$ & $\begin{array}{l}\text { Team grading } \\
\text { MI workshop } \\
\text { Training class } \\
\text { Other }\end{array}$ & $\begin{array}{l}50 \%(n=7) \\
36 \%(n=5) \\
7 \%(n=1) \\
7 \%(n=1)\end{array}$ \\
\hline & $\begin{array}{l}\text { Perception of own ability to assess students' } \\
\text { application of spirit of MI } \\
\text { (respondents }=11 \text {, total responses }=13 \text { ) }\end{array}$ & $\begin{array}{l}\text { Limited by time constraints } \\
\text { Able to assess } \\
\text { Unsure about effectiveness of MI }\end{array}$ & $\begin{array}{c}69 \%(n=9) \\
23 \%(n=3) \\
8 \%(n=1)\end{array}$ \\
\hline & $\begin{array}{l}\text { Perception of own ability to model spirit } \\
\text { of MI with students and patients in clinic } \\
\text { (respondents=5, total responses }=6 \text { ) }\end{array}$ & $\begin{array}{l}\text { Model spirit of MI on a limited basis } \\
\text { Time constraints } \\
\text { Other }\end{array}$ & $\begin{array}{l}66 \%(\mathrm{n}=4) \\
17 \%(\mathrm{n}=1) \\
17 \%(\mathrm{n}=1)\end{array}$ \\
\hline \multirow[t]{3}{*}{$\begin{array}{l}\text { Motivational } \\
\text { Interviewing } \\
\text { Qualitative Faculty } \\
\text { Questionnaire }\end{array}$} & $\begin{array}{l}\text { Suggestions for how to maintain confidence } \\
\text { in supporting students' delivery of } \mathrm{MI} \\
\text { (total responses } \mathrm{n}=8 \text { ) }\end{array}$ & $\begin{array}{l}\text { Professional development/in-service } \\
\text { Team grading } \\
\text { Student MI test case } \\
\text { MI video examples }\end{array}$ & $\begin{array}{c}50 \%(\mathrm{n}=4) \\
25 \%(\mathrm{n}=2) \\
12.5 \%(\mathrm{n}=1) \\
12.5 \%(\mathrm{n}=1)\end{array}$ \\
\hline & $\begin{array}{l}\text { Suggestions for maintaining positive } \\
\text { influence on students' use of MI in clinic } \\
\text { (total responses } n=8 \text { ) }\end{array}$ & $\begin{array}{l}\text { Application of Ml strategies } \\
\text { Student MI test case (non-recorded) } \\
\text { Provide MI dialogue examples to faculty }\end{array}$ & $\begin{array}{c}37.5 \%(n=3) \\
37.5 \%(n=3) \\
25 \%(n=2)\end{array}$ \\
\hline & $\begin{array}{l}\text { Suggestions to assist students in recognizing } \\
\text { faculty members' modeling spirit of Ml } \\
\text { (total responses } n=7 \text { ) }\end{array}$ & $\begin{array}{l}\text { MI should occur throughout the } \\
\text { appointment } \\
\text { Enhance DHPOC form to have MI } \\
\text { strategy section } \\
\text { Other }\end{array}$ & $\begin{array}{r}37.5 \%(n=3) \\
25 \%(n=2) \\
25 \%(n=2)\end{array}$ \\
\hline
\end{tabular}

Note: On the three items in posttest 2, participants provided more than one response each.

suggested applying MI strategies with students during patient care, and $37.5 \%(\mathrm{n}=3)$ recommended a student MI test case (non-recorded) requirement. Respondents also suggested using MI throughout the patient's appointment to assist students in recognizing faculty members' modeling the spirit of MI.

\section{Discussion}

In this study, the majority of the faculty members expressed that it was important to personally embrace the overall spirit of MI during patient care, and they were confident supporting students as well. However, their rating for embracing the spirit of MI increased from pretest to posttest 1 , but slightly decreased by posttest 2 . This trend was also evident in their assessment of the importance of and their confidence in facilitating the eight MI strategies over time.

We hypothesized that professional development activities would enhance the participants' perceptions of both importance and confidence regarding 
MI. This hypothesis was affirmed by the increase in scores immediately following the MI workshop (posttest 1) held right before the start of the academic year. This result was consistent with the findings of Brand et al. that both importance of and confidence in applying MI increased after training. ${ }^{9}$ However, the general decrease in the faculty members' perceptions of both importance and confidence by the end of the academic year needs further exploration.

Studies by Miller et al. and Hinz concluded that MI training should use a multi-modal approach that includes coaching and feedback for long-term retention of skills. ${ }^{17,19}$ As part of the MI faculty development in our study, the clinical faculty members were invited to participate in team grading of student-patient MI recordings over three semesters. For these activities, however, faculty members were not required to participate; for those who did not, it was due to either scheduling constraints or a personal decision to not be involved. Interestingly, of those who did participate, all found those sessions very helpful in supporting student delivery of MI. These findings suggest it may be useful to make the sessions mandatory in the future.

For nearly half of the faculty members who participated in this study, there was an eight-month gap between MI training and the end-of-year assessments, which aligned with a decrease in their perceptions of importance and confidence on posttest 2 . These results support Miller et al.'s findings that training with coaching and feedback improved retention and that, when feedback was not provided, MI skills decreased over time. ${ }^{17}$ Curry-Chiu et al. found that faculty training and buy-in were important aspects of implementing MI in a curriculum. ${ }^{18}$ Their study also reported that continual faculty training and support were needed for retention of MI skills.

On the pretest, posttest 1 , and posttest 2 in our study, there were five questions about the participants' perceptions of students' ability to use MI strategies and the amount of time in clinic to incorporate MI. In addition, the participants were asked their perceptions of their own skills and ability to be a positive influence in facilitating students' use of MI strategies. At the end of the MI workshop, the participants' perception that students had adequate time to incorporate MI strategies increased; that finding may be related to the momentum immediately following the workshop. The fact that the participants' perceptions peaked immediately following the MI workshop also supports Curry-Chiu et al.'s finding about the value of MI faculty training to provide skills needed for faculty to support students' use during patient care. ${ }^{18}$ Croffoot et al. also found that dental hygiene students improved their MI skills after receiving coaching and feedback from faculty members who had attended a two-day training session. ${ }^{10}$

By the end of the academic year, however, the perceptions of the faculty members in our study had decreased regarding being a positive influence on students' use of MI strategies. Time constraints were frequently mentioned by the participants as the greatest challenge in assessing and providing feedback to students. This finding aligns with Mills et al.'s study in which students also reported feeling time constraints were a challenge to incorporate MI strategies during patient care. ${ }^{22}$ Rollnick et al. suggested that BMI instead of full MI be used by providers with limited time and that use of BMI may allow faculty to better support and provide feedback to students. ${ }^{8}$

The Motivational Interviewing Qualitative Faculty Questionnaire provided valuable insights for our study, especially since faculty confidence in facilitating the eight MI strategies and supporting students' embracing the spirit of MI decreased over time. However, the fact that half of the participants did not complete the questionnaire was unexpected.

The respondents' recommendations for maintaining their confidence included professional development activities, in-service, and team grading. These results aligned with other studies that found training to implement MI should include education tools, coaching, feedback, and follow-up coaching/ feedback regarding performance in order to achieve long-term sustainability. ${ }^{10,19}$

The limitations of this study included a small number of participants and a lack of control or comparison groups for the dental hygiene faculty members who participated, potentially impacting the validity of the results. This study's participants were at only one institution, limiting the generalizability of its results. In addition, since all faculty members participated in the MI workshop but not all of them participated in the team grading, it is not possible to distinguish the effects of one intervention from the other. Finally, the study did not attempt to identify any additional factors beyond the MI workshop and team grading sessions that may have affected the participants' attitudes about or use of MI during any of the assessment periods, so any confounding variables remain unknown. Carefully designed, multi-institution longitudinal studies on the impact of MI professional development activities, including team grading, should be conducted to address these 
limitations and provide further understanding of the most effective ways to prepare dental hygiene faculty members to teach MI to their students.

\section{Conclusion}

This study found that a faculty development workshop in MI increased dental hygiene faculty members' appreciation of the value of MI and confidence in teaching it to students immediately after the workshop. However, both measures decreased from immediately after the workshop to the end of the academic year. Half of the faculty members also took part in team grading sessions on MI, which those participants reported enhanced their perceptions about and teaching of MI. The addition of faculty incentives and modifying schedules to increase participation in MI professional development activities should be considered. In addition, an MI refresher in-service should be provided during the academic year with the inclusion of more BMI activities for faculty members due to reported time constraints.

\section{Acknowledgments}

The authors thank Kimberly Bray, RDH, MS, and Delwyn Catley, $\mathrm{PhD}$, from the University of Missouri-Kansas City, for facilitating the workshop and designing the assessment instrument that we adapted for use in our project. In addition, gratitude is extended to Corey Powell, $\mathrm{PhD}$, for his assistance with the statistical analysis.

\section{REFERENCES}

1. Oral health in America: a report of the surgeon general. Rockville, MD: U.S. Department of Health and Human Services, National Institute of Dental and Craniofacial Research, National Institutes of Health, 2000.

2. Rhea M, Bettles C. Dental hygiene at the crossroads of change: environmental scan 2011-21. Chicago: American Dental Hygienists' Association, 2011.

3. Healthy People 2020. Determinants of health. 2015. At: www.healthypeople.gov/2020/about/foundation-healthmeasures/Determinants-of-Health. Accessed 17 Sept. 2016.

4. Healthy People 2020. Topics and objectives: oral health. U.S. Department of Health and Human Services. At: www. healthypeople.gov/2020/topics-objectives. Accessed 17 Sept. 2016.

5. Ramseier CA, Suvan JE. Health behavior change in the dental practice. Ames, IA: Wiley-Blackwell, 2010.

6. Miller WR, Rollnick S. Motivational interviewing helps people change. 3rd ed. New York: Guilford Press, 2013.
7. Mason P, Butler CC. Health behavior change: a guide for practitioners. 2nd ed. Edinburgh: Elsevier Churchill Livingstone, 2010.

8. Rollnick S, Mason P, Butler C. Health behavior change: a guide for practitioners. Edinburgh: Churchill Livingstone, 1999.

9. Brand VS, Bray KK, MacNeill S, et al. Impact of singlesession motivational interviewing on clinical outcomes following periodontal maintenance therapy. Int J Dent Hyg 2013;11(2):134-41.

10. Croffoot C, Bray KK, Black MA, Koerber A. Evaluating the effects of coaching to improve motivational interviewing skills of dental hygiene students. J Dent Hyg 2010;84(2):57-64.

11. Bray KK, Catley D, Voelker MA, et al. Motivational interviewing in dental hygiene education: curriculum modification and evaluation. J Dent Educ 2013;77(12):1662-9.

12. Gao X, Lo EC, Kot SC, Chan KC. Motivational interviewing in improving oral health: a systematic review of randomized controlled trials. J Periodontol 2014;85(3):426-37.

13. Lindson-Hawley N, Thompson TP, Begh R. Motivational interviewing for smoking cessation. Cochrane Database Syst Rev 2015;3:1-78.

14. González-Del-Castillo-McGrath M, Guizar-Mendoza JM, Madrigal-Orozco C, et al. A parent motivational interviewing program for dental care in children of a rural population. J Clin Exp Dent 2014;6(5):e524-9.

15. Hirsch GB, Edelstein BL, Frosh M, Anselmo T. A simulation model for designing effective interventions in early childhood caries. Prev Chronic Dis 2012;1-9.

16. Neff JA, Walters ST, Braitman AL, et al. A brief motivational intervention for heavy alcohol use in dental practice settings: rationale and development. J Health Psychol 2013;18(4):542-53.

17. Miller WR, Yahne CE, Moyers TB, et al. A randomized trial of methods to help clinicians learn motivational interviewing. J Consult Clin Psychol 2004;72(6):1050-62.

18. Curry-Chiu ME, Catley D, Voelker MA, Bray KK. Dental hygienists' experiences with motivational interviewing: a qualitative study. J Dent Educ 2015;79(8):897-906.

19. Hinz JG. Teaching dental students motivational interviewing techniques: analysis of a third-year class assignment. J Dent Educ 2010;74(12):1351-6.

20. Schwalbe CS, Oh HY, Zweben A. Sustaining motivational interviewing: a meta-analysis of training studies. Addiction 2014;109(8): 1287-94.

21. Kenny NP, Mann KV, MacLeod H. Role modeling in physicians' professional formation: reconsidering an essential but untapped educational strategy. Acad Med 2003;78(12):1203-10.

22. Mills A, Kerschbaum WE, Richards PS, et al. Motivational interviewing: assessment of dental hygiene students' perceptions of importance in using and confidence in applying. J Dent Hyg 2017;91(1):17-21.

23. Moyers TB, Martin T, Manuel JK, et al. Revised global scales: motivational interviewing treatment integrity 3.1.1. At: www.motivationalinterviewing.org/sites/default/files/ MITI\%203.1.pdf. Accessed 25 Oct. 2016. 